\title{
Open Access to ICT and Electronic Educational Resources as a Guarantee of Sustainable Development of Society
}

\author{
Vladyslav Velychko, ${ }^{1, *}$, Svitlana Omelchenko ${ }^{1}$ and Olena Fedorenko ${ }^{1}$ \\ ${ }^{1}$ Faculty of Physics and Mathematics, Donbas State Pedagogical University, 84122 Sloviansk, Ukraine \\ *Corresponding author. Email: vladislav.velichko@gmail.com
}

\begin{abstract}
Open education is one of the modern world trends. Ideas of open education are implemented through information and communication technologies that give students access to e-learning resources. ICT and education resources should be open and accessible for free use. The use of free software makes it possible to realize the openness of ICT use. The availability of educational content is realized through the use of open electronic educational resources. The use of information and communication technology and electronic educational resources for own learning and professional activity is possible with digital competence. The development of free software and e-learning resources is a complex and costly task. The development and creation of free software and open e-learning resources are done through a collective effort - crowdsourcing. The free software you create meets the free licensing requirements. The developed open e-learning resources are governed by the Creative Commons License Terms. Involving the pre-service teachers is helpful for developing of open e-learning resources. The use of open e-learning resources in the training of pre-service teachers has double importance. Pre-service teachers not only acquire new knowledge but they also acquire new skills as they develop electronic educational resources. In addition, the development of e-learning resources is a good practice for pre-service teachers.
\end{abstract}

Keywords: open electronic educational resources, development of open educational resources

\section{INTRODUCTION}

On September 15, 2017, the Government of Ukraine presented the National Sustainable Development Goals: Ukraine report [1]. It identifies basic indicators for achieving the Sustainable Development Goals. The report presents the results of the adaptation of the world goals as 17 global sustainable development goals for Ukraine.

In the presented report the fourth objective concerns education. It is about providing inclusive and equitable quality education and promoting lifelong learning for all. The government has developed seven objectives to achieve this goal. Five of them involve the use of information and communication technologies separately and in combination with other means. These include [1]: ensuring the availability of quality education for all children and adolescents, ensuring the availability of vocational education, improving the quality of higher education and communication with science, increasing the spread of knowledge and skills among the population to obtain decent work and entrepreneurship, creation of modern learning conditions in schools.

Monitoring the development of ICT skills in work and daily life is reflected in statistics on the dynamic growth of Internet users in Ukraine: from $22.0 \%$ in 2010 to $62.6 \%$ in 2018 (urban settlements $28.9-70,1 \%$, rural areas - 7.5-
$47.8 \%$ respectively) [2]. The distribution of the population by the place of use of Internet services indicates an increase in the share of home users. They make up to $62.6 \%$. Users of services at work are up to $92.4 \%$. Up to $45.9 \%$ of them use the Internet via a mobile phone. Considering the given data on access to the Internet we can state that the technical possibilities of access to electronic educational resources are accessible to the citizens of Ukraine. This raises the question of using the Internet for educational purposes.

In January 2018, the European Commission adopted, under Horizon 2030, a Communication on Action Plan on Digital Learning. This document identifies ways in which the EU can help citizens and educational institutions make the best use of digital learning technologies through [3]: improving the use of digital technologies in teaching and learning; developing relevant digital competences and digital transformation skills; improving education through better data analysis and prediction.

\section{PROBLEMS AND METHODOLOGY}

Digital literacy (or digital competence) is recognized by the EU as one of the keys to a person's full life and work. Article 12 of the Law of Ukraine "On Education" states that the formation of information and communication competence is key and obligatory to the formation [4]. 
Various measures have been taken to meet this requirement. These one include the study of aspects, principles and forms of the use of information and communication technologies in educational activities. The study of problems, technologies and concepts of preparation of subjects of educational activity to the application of information and communication technologies in professional activity. The creation and use of electronic educational resources is considered, a harmonious combination of various forms of organization of the educational process is investigated and tested in practice.

Another aspect of using ICT is to overcome digital inequality. The term "digital inequality" describes a situation that arises when social groups exist in society. The former has access to modern digital communication technologies (first and foremost, to the Internet), while the latter do not. Correcting of this situation lies through the implementation of ideas of open education:

- use of specialized technologies and training tools;

- test, automated quality control of knowledge;

- economic efficiency of educational activity;

- the opportunity to study at a convenient time, convenient location and convenient pace;

- the possibility of forming an individual curriculum that meets personal needs and a set of independent training courses:

- possibility of training in combination with professional activity;

- putting the functions of coordinating the cognitive process on the teacher, adjusting the content of the discipline, consulting in the preparation of individual curriculum, management of educational projects using information and communication technologies;

- increasing the requirements for self-organization, motivation, self-employment and hard work;

- introduction of information and communication technologies into training;

- - export and import of educational services.

From a technological point of view, the implementation of information and communication technologies is possible only through the use of free software. Free software is a social and philosophical phenomenon in the field of software. Free software provides the opportunity to implement any modern information and communication technology at the highest level.

\section{RESULTS AND DISCUSSION}

The phenomenon of free software originated in the depths of the academic (university and research) environment. Not surprisingly, initially computer software was mostly academic. For computer science professionals, each program was the result of a scientific study and was compared to the publication of an article. This means that the original text of the program must be made available to the entire scientific community, since any scientific result must be verified, that is confirmed by the results of other researchers and open to criticism. Thus, the software development process is in some ways identical to the scientific process: a scientist analyses existing programs, adjusts them or refines them according to their ideas, and publishes modified / improved program options - a new result (intellectual product like a scientific article).

Free software is distributed under the appropriate license terms. Open license agreements, despite their names, still have certain terms of use for the software. The minimum conditions are imposed by a license agreement called "Public domain". This license allows you to distribute, modify and use the software at your own discretion. The category "public domain" also includes software that has a copyright or a related right that has expired or never existed. Since the Berne Copyright Convention comes into effect automatically after the creation of a work, copyright and related rights must be abandoned in order to waive copyright and related rights. In the world, this means that you must give up your copyrights and safeguards for their preservation, which is realized through the use of $\mathrm{CC} 0$, Unlicense or even WTFPL licenses.

Open licenses also include "license" (academic, permissive) licenses. For example, BSD, MIT, Apache license agreements [5]. Such licenses appear on software products created in the academic environment. For students, graduate students, and scholars, the dissemination of their development is an important point in the publication of their own research. In fact, licenses are similar to general licenses except for non-copyright. The licenses not only allow open source to be used for any of its own purposes, but also use it in commercial and proprietary software.

The next class of open licenses are those based on the support of the copyleft principle. The basic idea of this class is to maintain the claimed rights and freedoms of the software product, which was created on the basis of the original. According to the Free Software Foundation, free software cannot be used to create proprietary software. Thus, free software released under the right copyleft can serve as the basis of only free software. The GNU GPL (General Public License) is an example of such license. There is a "weakened" version of the LGPL (Lesser General Public License). It allows you to build software with non-GPL licensed libraries. This option allows the interaction of free and proprietary software. We are very impressed with D. Devi's work [6], which describes the issue of the interaction of various open licenses with adaptation to the present day.

In the course of the study, we found that each stakeholder may have his or her special open license, or copyleft, or a simple license. This eventually led to a problem of compatibility. Licenses are compatible if you continue to distribute free software and one license may be changed to another. In other words, if the licenses are compatible, then the user (licensee) of any open source program may assign (license further) rights to the program (its modification) under a different license, different from the license under 
which the original program was obtained by that user. Incompatibility of licenses leads to a restriction on the freedom to distribute free software, so it destroys the main purpose of the movement for free software. For example, two copyleft licenses are incompatible with each other only when each of them establishes that any modifications to the program may continue to be subject to the terms only of the license under which the developer who made the modification received the original program.

\subsection{Digital Competence}

The Joint Research Centre (JRC) of the European Commission summarizes its research into the role of the person in the digital era "Learning and Skills for the Digital Era" highlighting the following areas of research: skills and competences, innovation and modernization of education and training, open education [7].

Because modern society is characterized by rapid progress and growth in technology. This directly causes changes in the directions of human activities and becomes a driving force for the transition of society to the information society. There is a need for non-standard thinking professionals who are well-versed in the information space and able to make quick decisions. Specialists are changing the priorities in the field of education and requirements for the existing competences.

The Law of Ukraine "On Education" emphasizes the comprehensive development of a person "as a person and the highest value of a society, his or her talents, intellectual, creative and physical abilities. On the formation of values and competencies necessary for successful self-realization. To educate responsible citizens, capable of making informed public choices and directing their activities for the benefit of others and society. Enriching the intellectual, economic, creative and cultural potential of the Ukrainian people, enhancing the educational level of citizens to ensure the sustainable development of Ukraine and its European choice [4]. The law also refers to competence which is a dynamic combination of knowledge, skills, ways of thinking, attitudes, values, other personal qualities that determines a person's ability to successfully socialize, pursue professional and further educational activities [4]. Chapter 18 of this law states that postgraduate education provides for ,the acquisition of new and improvement of previously acquired competences on the basis of higher education obtained and the acquisition of a new person or improvement of previously acquired competences in the field of professional activity or field of knowledge [4].

Today, the term "digital competence" is used in the educational space to describe ICT skills. So, speaking about the necessary competencies of the modern specialist in the era of global informatics, it is necessary to distinguish the very concept - digital competence.

The review of the category "digital competence" began at the beginning of the 21st century and in 2006. Digital competence has been recognized as one of the key competences in the context of lifelong learning within the framework of the European Union Recommendations. Digital competence is the ability to use information and communication technologies confidently, critically and creatively to achieve goals. These goals relate to the fields of professional development, employment, training, leisure and participation in society. Digital competence contributes to the achievement of other competences in the fields of languages, mathematics, learning, cultural awareness and more. Digital competence refers to the 21 st century skills that all citizens must attain in order to ensure their active participation in society and its economic development [8]. In 2018, the Digital Competence Framework for DigCompEdu (Digital Competence Framework for Educators) was developed by the European Commission's Joint Research Centre [9]. It describes in details the digital competence of the teacher. This standard is aimed at teachers and teachers of all levels of education, from preschool to higher education and adult education. The application of digital competence is envisaged in general and professional education. In the education of people with special needs, in various forms of educational activities. The focus of the document is on detailing the use of digital competency for innovation in education.

The existing digital competence of a specialist implies confident use of information and communication technologies. The use of information and communication technologies to create, search, process, disseminate and exchange information in a professional activity and for their own needs.

The problem of formation of digital competence as a component of professional competence, effective use of information and communication technologies in education, construction of educational activity by means of digital educational technologies has been investigated by many domestic and foreign scientists. The essence and structure of digital competence and digital culture are described in the works of R. Gurevich, A. Gurjii, M. Zhaldak, N. Morse, O. Spirin and others. Problems of formation of professional competences using digital educational technologies are considered in works by R. Gurevich, N. Morse, O. Spivakovsky and others. The use of digital educational technologies in higher education is covered in the works of V. Bykov, O. Glazunova, M. Shishkina and others. Digital competence is one of the professionally significant competences. Digital competence is the skill of an educator to use information technology in their professional activities [10], the ability to use electronic educational resources and information and communication technologies, to understand and be able to critically evaluate digital resources and content, to collaborate effectively [11], the sum of common user and professional knowledge, skills and competencies represented in different models of ICT competency [12]. The components of digital competence include knowledge, skills, abilities and attitudes, technical skills of ICT work, the ability to use resources in the educational process, the ability to plan, analyse and manage the educational and educational process through information and communication technologies [13]. 
Digital competence has several substantive components: working with digital content (creation, search, use, storage, aggregation, etc.); solution of technical problems (analysis of work of computer equipment, multimedia equipment, peripheral equipment, interaction of hardware and software components, creation of network channels of interaction); digital communication (communication using digital technologies, publication of documents online, ethics of communication); data analysis (data collection, data analysis, data visualization, infographics, etc.); information security (risks and threats of information interaction, protection of personal data, secure use of digital devices). Exactly in these areas the future teachers are trained.

Information and communication technologies are one of the fast-moving industries of humanity now. Information and communication technologies are constantly changing and the speed of this process is increasing every year. In order for the digital competence of practicing teachers to be relevant, it is necessary to lay the foundations of digital competence at the level of basic competences during the training. With just such basic knowledge, future teachers will be able to acquire new knowledge and skills throughout their lives. The formation of basic fundamental skills occurs during the study of computer science, through the use of information and communication technologies in teaching any academic discipline and the widespread use of digital content in the educational process, in the execution of research projects. The list also includes support for selfeducational activities, non-formal learning, blended and inverted forms of learning activities, etc. Important one in this area is the use of distance learning systems in the training of future teachers [14].

\subsection{Open e-learning resources}

Modern, open standards-based electronic educational resources can be created using free software. An analysis of the development of technologies for creating electronic educational resources shows that closed proprietary formats do not stand up to competition with the free ones. Electronic educational resources are created mainly through the same forms of crowdsourcing as free software. Both teachers and students participate in their creation in the framework of research activities. Most of the first elearning resources were digital versions of print editions, largely without the didactic possibilities of presenting material using multimedia technologies. Today, an understanding has emerged that an electronic educational resource should contain multimedia, audio and video components that enhance the presentation of material. However, most scientific and pedagogical staff lack knowledge, skills, and often time to create an e-learning resource of good quality. The key to creating a successful online educational resource with interesting and engaging content is the talent and skill of the co-authors.

Open education is inseparable with e-learning. The ideology of open education is realized solely through the use of information and communication technologies. The latter, in turn, transform educational activities into e- learning. Thus, e-learning should be considered as a direct implementation of open education. Features of open education correspond to the features of e-learning, namely: e-educational resources are the carriers of knowledge and skills; the role of the teacher is changed, the absence of age and time constraints is emphasized; self-educational activity is activated; comprehensive use of information and communication technologies.

We are convinced that e-learning is a manifestation of the impact of information and communication technologies on human educational activities. This is the combination of the use of Internet technologies, the opportunities of information and communication technologies and the goal of translating education into a new format. E-learning changes the forms and content of the educational process by allowing information to be received and interacting with the subjects of the educational process, regardless of time and place; provides use of modern forms of education; opens new opportunities for remote communication and information exchange; enhances the quality of teaching and the effectiveness of scientific and research activities.

E-learning development environments are focused on developing e-learning resources. The high standards that society puts forward for education today require the adaptation, personalization and dynamic focus of electronic educational resources. With the continuous increase of sources of information and the availability of developed training resources, it becomes increasingly difficult to control and update them manually, to recommend the most appropriate for a particular person and specific educational goals. For this reason, content development and direct management of future mathematics, physics and informatics teachers' learning activities are increasingly giving way to software development to automate the creation of electronic educational resources, collaborate on development processes, and automatically adapt them to specific contexts. Therefore, one of the major trends in the development of e-learning environments is the improvement of their software development tools and, as a consequence, the transformation of their future teachers of mathematics, physics and computer science into integrated environments for the development and management of educational resources.

The use of ICT in open education is only possible if free software is used, since free software meets the requirement of availability anywhere, anytime. The use of free software will allow access to e-learning resources, use e-learning and translate the ideas of open education into the future professional activities of future teachers of mathematics, physics and computer science. Let us consider in more detail the application of free software to the future professional training of mathematics, physics and computer science teachers. The following list includes:

- access any electronic educational resources;

- create e-learning resources, including interactive ones;

- perform computational experiments;

- to study physical processes using modelling methods; 
- find and investigate patterns in any process;

- process empirical data;

- to present own educational and scientific activity;

- to participate in professional communities;

- raise their professional level;

- build a personal learning trajectory.

The result of the introduction of the ideas of open education into the teaching activities of future teachers of mathematics, physics and computer science is the preparation for active and fruitful life in the information society, ensuring the quality, accessibility and effectiveness of education, creating educational conditions for lifelong learning through the wide implementation of education methods and means of information and communication technologies and computer-oriented technologies. In order to achieve this result, in terms of pedagogical science, it is necessary to fulfil certain conditions:

- substantiation of possibilities of using information and communication technologies that will become the basis of new educational technologies;

- detailed elaboration of basic provisions, laws, principles, relations, relationships and conditions of development of information and communication technologies in educational activity;

- development of a conceptual model of teaching in the information-educational environment on the basis of comprehension, modernization of didactic concepts and principles of the traditional model of teaching, selection and justification of new didactic principles that will contribute to quality learning in the information-educational environment;

- creation of a formalized model of training in the information and educational environment, which involves the development of information tools for training, testing; methods of teaching and selfeducational activity in the information-educational environment, taking into account the individual characteristics of the subjects of the educational process and the psycho-didactic requirements of the organization of training.

Opportunities for open e-learning should be considered in the practical training of future teachers and digital competencies. Open e-Learning resources play a crucial role in digital competence. With the help of open electronic educational resources theoretical and practical training of future teachers is provided. Creating and adapting open elearning resources is a necessary element of the professional training of future teachers.

The use of open e-learning resources was explored by D. Wiley and J. Hilton. They have developed criteria for the importance of creating and adapting open e-learning resources for their own needs. The following criteria of significance include [15]:

- Are students asked to create new artefacts (essays, poems, videos, songs, etc.) or revise/remix existing OER?
- Does the new artefact have value beyond supporting the learning of its author?

- Are students invited to publicly share their new artefacts or revised/remixed OER?

- Are students invited to openly license their new artefacts or revised/remixed OER?

Each of these points reinforces the importance of creating open e-learning resources in the preparation of future teachers. The first criterion is the creation of open elearning resources which is an integral part of the future teacher training. It is this point that requires future teachers to be introduced to open e-Learning resources, opportunities and classifications by type.

The following paragraph meets the requirement to develop and create open e-learning resources that can be used by other participants in the educational process. It is this requirement that leads to the creation of an open electronic educational resource which will be useful not only for its author, as an experience of creation. At this point, future teachers are aware of the social importance of their professional activities. The development and creation of an electronic educational resource requires theoretical knowledge of the psychology of perception and processing of information, educational activities, teaching methods of the discipline and more.

The following paragraph about the publication of a developed e-learning resource is testing future teachers' readiness for public activity. The specificity of the future teachers' professional activity is openness to other participants in the educational process, and free knowledge of open communication skills is a necessary component of vocational training. This requirement also includes the development of educational resources, including electronic ones.

The fourth point imposes the need for open use of elearning resources developed by future teachers. In the future, future teachers have the opportunity to use publicly available educational resources that have been previously developed. Combining this with the social work of future teachers, the demand becomes more natural. And implementation of each of these points leads to the formation of competence in the development and creation of open electronic educational resources.

The practical implementation of the proposed method is proposed by J. Van Allen and S. Katz in their study [16]. The authors proposed three steps to transform the existing training course into open e-learning resources. Let's summarize the experience described. The first stage is an analysis of the existing training course on the use of open e-learning resources in its study. The suitability of the course for the use of open e-learning resources will take place even when printed materials are used in its study. The next step of the first stage is to analyse the possibility of presenting the training material using open licenses for its publication. Not every educational material can be made publicly available. There are branches of science where public distribution of material is prohibited. There are no such bans to prepare future teachers. 
The selection of educational material should be very careful and the educational material itself should be multifaceted. There are various means of collecting educational content for the selection of educational material. These tools can work both automatically (keyword selection) and through user actions (storing the necessary materials and links while exploring online material available). The diversity of materials, the author's different presentation of the issues under consideration lead to an increase in his understanding.

In the second stage, the evaluation of the collected educational material is carried out according to the criteria of D. Wiley and J. Hilton, adaptation of the educational material to the application in e-learning, definition of the platform for e-learning and exchange of open electronic educational resources. The material collected in the first stage requires critical analysis and processing. It is necessary to define standards for the exchange of open electronic educational resources and the platform on which the materials will be exchanged.

The third stage involves the implementation of the developed e-learning resource on one of the available resources. The L. Morris study reviewed current systems for the accumulation and dissemination of open electronic educational resources [17]. The creation of open e-learning resources is an effective result of the learning technology the project method. It is necessary to transform individual and group tasks of the discipline into a large-scale educational project. The result of the project is the development and creation of an e-learning resource that will be useful for students. One of the Creative Commons licenses is a developed e-learning resource. After that, we receive a ready-made open electronic educational resource, based on scientific principles of general pedagogy, the psychology of perception, teaching methods of discipline. In addition, future teachers gain useful practical experience of applying their knowledge and practical professional skills.

The stages of development of open electronic educational resources are presented in Fig. 1. One of the possible implementation options is presented by the author in [18].

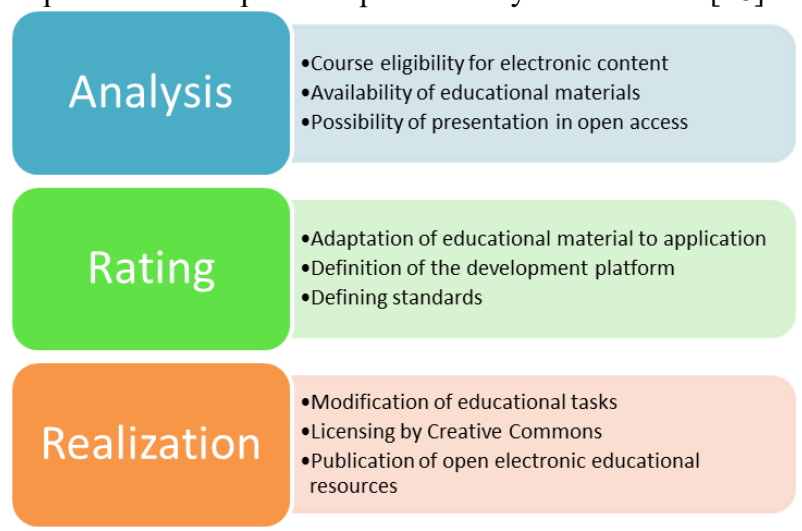

Figure 1. Stages of development of open electronic educational resources during the educational activity

\section{CONCLUSION}

Provision of inclusive and equitable quality education and the promotion of lifelong learning for all is one of the priorities of the sustainable development of society. Comprehensive education is realized through the implementation of open education ideas, in which open electronic educational resources play a crucial role. Future open-source, open-source e-learning resources developed by future teachers are expanding the learning content available. Future teachers, at the same time, acquire the skills of teamwork, participation in projects and increasing the level of formation of information and communication technologies for their own and professional needs.

\section{REFERENCES}

[1] Sustainable Development Goals, Ukraine. Ministry of Economic Development and Trade, 2017.

http://un.org.im/images/SDGs_NationalReportUA_Web _1.pdf, last accessed 2019/12/01 (in Ukrainian)

[2] Household Internet Access in 2018 year, State

Statistics Service of Ukraine, 2019.

http://www.ukrstat.gov.ua/druk/publicat/kat_u/2019/zb/ 07/zb_Internet_2018.pdf, last accessed 2019/12/03 (in Ukrainian)

[3] Digital Education Action Plan. European

Commission, Brussels, 2018. https://eur-

lex.europa.eu/legalcontent/EN/TXT/PDF/?uri=CELEX:52018DC0022\&fro $\mathrm{m}=\mathrm{EN}$, last accessed 2019/11/28

[4] Law of Ukraine "On Education", https://zakon.rada.gov.ua/laws/show/2145-19, last accessed 2019/11/29 (in Ukrainian)

[5] Rosen L., Open Source Licensing: Software Freedom and Intellectual Property Law, Upper Saddle River. NJ: Prentice Hall PTR, 2004

[6] Muruli Devi D., Copyleft Licenses for Repositioning the Frontiers of Open Access Environment: An Evaluation, 11th International CALIBER-2017, 2017

[7] Learning and Skills for the Digital Era, The European Commission's science and knowledge service. https://ec.europa.eu/jrc/en/research-topic/learning-andskills, last accessed 2019/12/12

[8] Ferrari A., Digital Competence in Practice: An Analysis of Frameworks. European Commission Joint Research Center. Institute of Prospective Technologies Studies. European Union, 2012. 
[9] Digital Competence Framework for Educators (DigCompEdu), The European Commission's science and knowledge service.

https://ec.europa.eu/jrc/en/digcompedu, last accessed $2019 / 12 / 22$

[10] Krumsvik R., Jones L., Teacher's Digital Competence in Upper Secondary School. ICITE 2013 Proceedings. http://www.icicte.org/Proceedings2013/Papers\%202013 /05-1-Krumsvik.pdf, last accessed 2019/12/13

[11] Scott C., The Futures of Learning 3: What kind of pedagogies for the 21 st century? UNESCO Education Research and Foresight, Paris. [ERF Working Papers Series, 15].

http://unesdoc.unesco.org/images/0024/002431/243126e .pdf, last accessed 2019/12/11

[12] Soldatova G., Zotova E., Lebesheva M., Shlyapnikov V., Internet: capabilities, competencies, security. Toolkit for employees of the general education system, Google, 2013, http://detionline.com/assets/files/research/BookTheorye.pdf, last accessed 2019/11/28 (in Russian)

[13] Prohorova S., The concept of digital competence of a foreign language teacher in a global educational space.
Bulletin of Zhytomyr Ivan Franko State University. 4, pp. 113-116, 2015.

http://nbuv.gov.ua/UJRN/VZhDUP_2015_4_24, last accessed 2019/12/22 (in Ukrainian)

[14] Velychko V., Implementation of distance learning in the retraining of computer science teachers. Problems of labor and vocational training. Sloviansk: SDPU, 14,pp. 187-191, 2009 (in Ukrainian)

[15] Wiley D., Hilton III J. L., Defining OER-enabled pedagogy. The International Review of Research in Open and Distributed Learning, 19(4), 2018. https://doi.org/10.19173/irrodl.v19i4.3601

[16] Jennifer van A., Katz S., Developing Open Practices in Teacher Education: An Example of Integrating OER and Developing Renewable Assignments. Open Praxis 11, 3, pp. 311-319, 2019.

[17] Morris L.V., Contemplating Open Educational Resources. Innovative Higher Education 44, Issue 5. pp. 329-331, 2019. https://doi.org/10.1007/s10755-01909477-7

[18] Velychko V., Creating E-learning Means of Free Software, Information Technologies and Learning Tools, Vol. 60, 4, pp. 128-140, (2017). https://doi.org/10.33407/itlt.v60i4.1619 (in Ukrainian) 